\title{
Downregulation of human epidermal growth factor receptor 2 by short hairpin RNA increases chemosensitivity of human ovarian cancer cells
}

\author{
LI SHAN MA ${ }^{1}$, QI YAN ${ }^{2}$, YONGFANG HUANG ${ }^{2}$, WENXIA ZHAO ${ }^{2}$ and YU ZHU ${ }^{2}$ \\ ${ }^{1}$ Department of Obstetrics and Gynecology, Yangpu Hospital Affiliated to Tongji University, Shanghai 200090; \\ ${ }^{2}$ Department of Obstetrics and Gynecology, Jiangwan Hospital, Shanghai 200434, P.R. China
}

Received May 7, 2014; Accepted January 16, 2015

DOI: $10.3892 / 01.2015 .3033$

\begin{abstract}
The aim of the current study was to investigate the suppressive effects of pSilencer T7-human epidermal growth factor receptor 2 (HER2)-short hairpin RNA (shRNA) recombinant plasmids on human SKOV3 ovarian cancer cell growth and sensitivity to carboplatin (CBP). Three different pairs of shRNAs (shRNAa, shRNAb and shRNAc), targeting the HER2 gene, were selected and transfected into human SKOV3 cells, respectively. The expression levels of HER2 were then detected by immunohistochemical (IHC), semi-quantitative reverse transcription-polymerase chain reaction and western blot analyses. In addition, cell cycle and cell growth were investigated using cell counting kit-8 (CCK-8). The results of the IHC and western blot analyses revealed that shRNAb significantly inhibited HER2 protein expression in SKOV3 cells. shRNAb exhibited an improved effect on HER2 expression compared with shRNAa $(\mathrm{P}<0.01)$, while shRNAc did not affect HER 2 expression. Nontransfected and nonspecific shRNA groups were used as the negative controls. Knockdown of HER 2 expression by shRNA was initiated at $24 \mathrm{~h}$ following transfection, achieving an optimum effect at $48 \mathrm{~h}$ and lasting for at least $72 \mathrm{~h}$ after the treatment. The CCK- 8 cell growth assay indicated that the knockdown of HER2 expression in the SKOV3 cell line resulted in significant growth suppression and cell cycle arrest. In addition, inhibition of HER2 significantly increased SKOV3 cell sensitivity to CBP treatment. In conclusion, pSilencer T7-HER2-shRNA significantly inhibited HER2 expression in human ovarian cancer cells in vitro and induced chemotherapeutic sensitivity to CBP.
\end{abstract}

Correspondence to: $\mathrm{Dr} \mathrm{Yu}$ Zhu, Department of Obstetrics and Gynecology, Jiangwan Hospital, 22 Chang Zhong Road, Shanghai 200434, P.R. China

E-mail: zhyzhy1971@163.com

Key words: short hairpin RNA, human epidermal growth factor receptor 2 , SKOV3 cells, ovarian cancer, chemosensitivity

\section{Introduction}

Ovarian cancer, including mucinous, serous, endometrioid, clear cell and metastatic carcinomas, exhibits the highest mortality rate of all the gynecological malignancies (1). Ovarian cancer is highly malignant and its incidence is increasing $(2,3)$, partly as a result of inadequate treatment strategies and the asymptomatic nature of the disease. Currently, standard treatments include surgery and systemic chemotherapy (4). Significant progress has been achieved with regard to chemotherapy and radiotherapy treatment for ovarian cancer; however, the overall five-year survival rate for ovarian cancer remains extremely poor. Thus, it is important to further elucidate the molecular mechanisms of ovarian cancer cell proliferation, differentiation and survival to aid the development of an optimal treatment (5). All diseases, including tumors, involve specific genes. Oncogenes are widespread, and the key gene may be considered as a 'gene trigger' (6); thus, the inhibition of the 'gene trigger' may improve cancer treatment. Numerous genes have been found to be involved in the occurrence and development of ovarian cancer. Therefore, these genes may used as potential therapeutic targets. Human epidermal growth factor receptor 2 (HER2), is a transmembrane receptor tyrosine kinase that is part of the epidermal growth factor receptor (EGFR) family $(7,8)$. Previous studies have demonstrated that the HER2 signaling pathway plays a critical role in carcinogenesis through the promotion of cell proliferation and differentiation (9-11). Furthermore, HER2 overexpression has been identified in a variety of cancer cell lines, indicating that HER2 may be a promising therapeutic target (12). The overexpression of HER2 is also associated with poor prognosis in ovarian cancer. Previous studies have revealed that the inhibition of HER 2 expression in human cancer cells leads to the suppression of cancer cell proliferation in vitro and tumorigenicity in vivo $(13,14)$. HER 2 expression may be inhibited by treatment with trastuzumab $(15,16)$, antisense oligonucleotides (17), decoy oligonucleotides (18) and miR-125b (19). Furthermore, the downregulation of HER2 activity and expression by decoy oligonucleotides, antisense oligonucleotides or small interfering RNA has been found to induce cancer cell apoptosis and growth arrest, while decreasing transforming growth factor and EGF secretion, 
thus inhibiting cancer cell growth $(20,21)$. In addition, studies have identified a number of apoptosis-associated genes, including cyclin D1 and B-cell lymphoma-extra large, which are involved in HER2 downregulation-induced cancer cell growth inhibition (22).

RNA interference (RNAi) is a biological technology commonly used to silence the expression of specific genes. Double-stranded RNA with a sequence complementary to the gene of interest is introduced into cells, leading to the rapid degradation of targeted messenger RNA (mRNA). This technology is a key method used in scientific research (23).

In the present study, immunohistochemical (IHC) analysis was initially used to investigate tumor samples from Yangpu Hospital Affiliated Tongji University (Shanghai, China). Subsequently, three different short hairpin RNAs (shRNAs) targeting the human HER2 gene were designed, constructed and transfected into human SKOV3 ovarian cancer cells. The aim was to downregulate HER2 expression and induce cancer cell growth. The effect of RNAi treatment on chemosensitivity to carboplatin (CBP) was also investigated.

\section{Materials and methods}

IHC analysis. A total of 106 ovarian cancer tissue samples from patients with various categories and stages of ovarian cancer and 20 normal ovarian tissue samples were freshly collected during surgery and biopsy, respectively, at Yangpu Hospital Affiliated Tongji University between July 2007 and October 2012. The 106 ovarian cancer patients included 37 cases of serous carcinoma, 43 cases of endometrioid adenocarcinoma, 17 cases of ovarian clear cell carcinoma and nine cases of ovarian mucinous carcinoma. Of the 106 ovarian cancer patients, 16 cases were diagnosed as stage I, 25 cases as stage II, 48 cases as stage III and 14 cases as stage IV, according to the International Federation of Gynecology and Obstetrics staging system (24). Samples were collected and fixed using $10 \%$ neutral formalin for the detection of HER2 expression. Patient tissues were then embedded in paraffin and cut into $5-\mu \mathrm{m}$ sections. SKOV3 cells (Shanghai Institute of Biochemistry and Cell Biology, Shanghai, China) were fixed onto slides, treated with $3 \%$ bovine serum albumin and incubated at $37^{\circ} \mathrm{C}$ for $5 \mathrm{~min}$, followed by primary rabbit anti-human polyclonal HER2 antibodies (1:100; cat. no. HE2-PR285; ACROBiosystems, Newark, DE, USA) and incubated at $4^{\circ} \mathrm{C}$ overnight. The slides were then washed three times with phosphate-buffered saline. Subsequently, the slides were incubated with rabbit anti-goat immunoglobulin (Ig)G polyclonal antibodies (1:12,000; cat. no. ABIN101255; antibodies-online Inc., Atlanta, GA, USA) for $30 \mathrm{~min}$ followed by streptavidin peroxidase (Shanghai ChangDao Biotech Co., Ltd., Shanghai, China) for additional $30 \mathrm{~min}$. Following deparaffinization, $3 \%$ hydrogen peroxide in methanol was applied for $10 \mathrm{~min}$ to block endogenous peroxidase activity. Next, the sections were treated with rabbit anti-human polyclonal HER2 antibodies (1:100; cat. no. HE2-PR285; ACROBiosystems), followed by horseradish peroxidase-conjugated goat anti-rabbit polyclonal IgG (1:1,000; cat. no. ab6721; Abcam, Cambridge, UK). Staining was performed at room temperature, using the avidin-biotin-peroxidase complex method (vectastain; Vector Laboratories, Inc., Burlingame, CA, USA). Images of each section were captured by the Empix image analyzer (Empix Imaging Inc., Mississauga, ON, Canada) at five random high-power fields (magnification, x400). Cells exhibiting a yellow or brown grainy stain were considered positive for HER2, while cells exhibiting no staining or light yellow stain were considered negative for HER2. The percentage of stained cells was used to determine the intensity of HER2 expression (low expression, $<25 \%$ positively stained cells; moderate expression, $25-50 \%$ positively stained cells; and high expression, $>50 \%$ positively stained cells). The images were scanned and divided into grids by the Empix image analyzer, which converted the pixels to mean grey values. The mean grey values were then analyzed by Northern Eclipse software version 6.0 (Empix Imaging Inc.), where grey values positively correlate with staining intensity. This study was approved by the ethics committee of Yangpu Hospital Affiliated Tongji University and written informed consent was obtained from all patients.

Cell culture and transfection. SKOV3 cells were grown in MacCoy's 5A Medium (PAN-Biotech GmbH, Aidenbach, Germany) containing $10 \%$ fetal bovine serum. Cells were seeded in 6-well plates and divided into five different treatment groups: Mock group; pSi-nonspecific (scrambled) shRNA group; and three pSi-HER2 shRNAs, including shRNAa, shRNAb and shRNAc. siPORT amine transfection agent (Ambion Life Technologies, Carlsbad, CA, USA) was used for plasmid transfection. Cell growth was determined using the cell counting kit-8 (CCK-8; Dojindo, Kumamoto, Japan). Cells were harvested 24,48 and $72 \mathrm{~h}$ after shRNA transfection to determine the protein and mRNA expression levels using western blot analysis and semi-quantitative reverse transcription-polymerase chain reaction (RT-PCR), respectively, while cell cycle analysis was also performed.

Semi-quantitative RT-PCR. A total of $1 \mu \mathrm{g}$ DNase-treated RNA was mixed with random primers $(3 \mu \mathrm{g} / \mu \mathrm{l}$; Invitrogen Life Technologies, Carlsbad, CA, USA), $2 \mu 110 \mathrm{mM}$ deoxyribonucleotides (Roche, Basel, Switzerland), $4 \mu 15 \mathrm{X}$ reverse transcriptase buffer (Roche), $0.5 \mu 1$ RNAs (Invitrogen Life Technologies), $2 \mu 10.1 \mathrm{M}$ dithiothreitol (Invitrogen Life Technologies) and $0.2 \mu 1$ avian myeloblastosis virus-reverse transcriptase (Roche), and incubated at $42^{\circ} \mathrm{C}$ for $1 \mathrm{~h}$. Following the generation of cDNA, PCR was performed under the following conditions. Total RNA was extracted using TRIzol reagent (Invitrogen Life Technologies). cDNA was synthesized from $2 \mu \mathrm{g}$ total RNA using the PrimeScript RT Reagent Kit (Takara, Bio, Inc., Otsu, Japan). The relative mRNA level for each gene was determined using a specific cDNA standard during the exponential phase of the PCR reaction. To quantify the expression of shRNAs, quantitative RT-PCR was performed using the ABI PRISM 7500 Sequence Detection System (Applied Biosystems Life Technologies, Foster City, CA, USA) under the following conditions: 35 cycles of predenaturation at $94^{\circ} \mathrm{C}$ for $5 \mathrm{~min}$, denaturation at $95^{\circ} \mathrm{C}$ for $45 \mathrm{sec}$ and annealing at $55^{\circ} \mathrm{C}$ for $30 \mathrm{sec}$. All the results were normalized to the housekeeping gene, $\beta$-actin. The $\mathrm{CT}$ values were calculated automatically using Rotor-Gene Real-Time Analysis Software version 6.0 (Qiagen, Inc., Valencia, CA, USA), and the quantity of expressed mRNA was calculated using the $2^{-\Delta \Delta C T}$ method (25). 

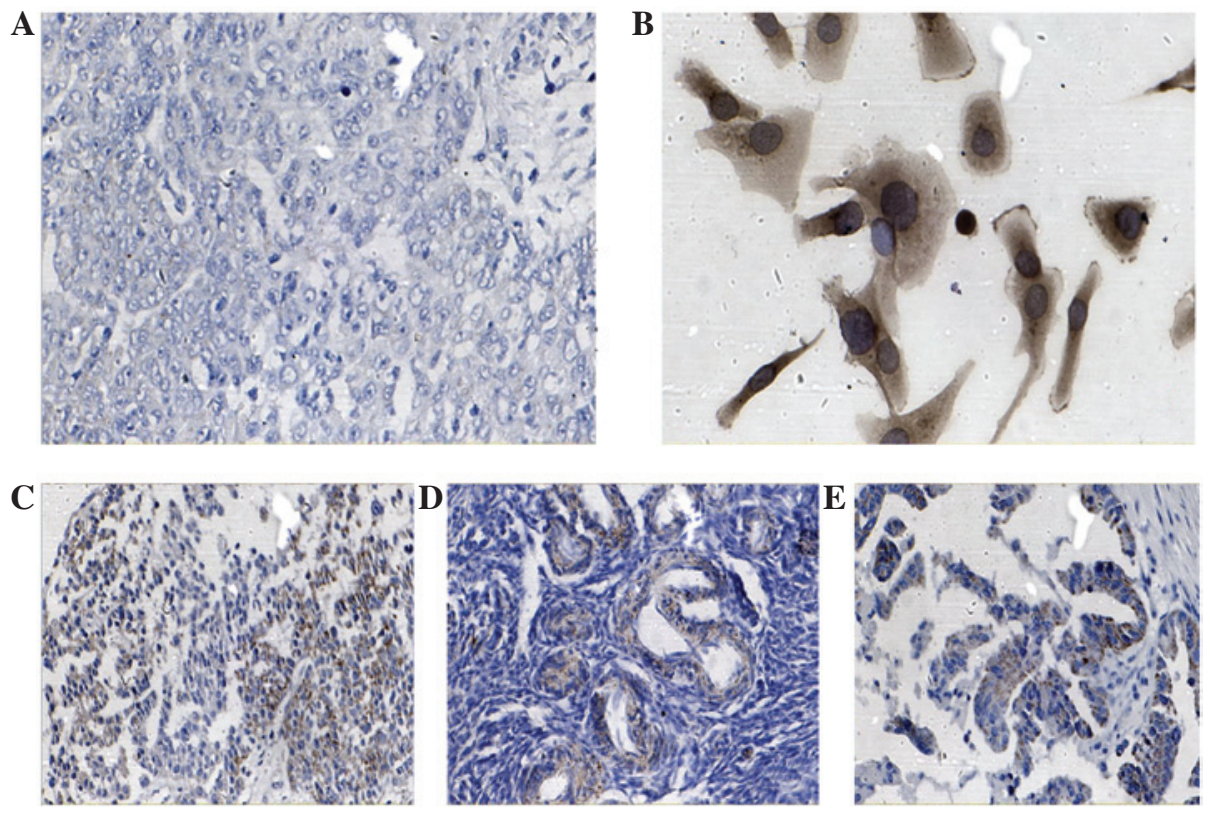

Figure 1. Low HER2 expression was found in (A) normal ovarian tissue, however, (B) SKOV3 cells, (C) clear-cell ovarian carcinoma, (D) ovarian serous cystadenocarcinoma and (E) ovarian endometrioid adenocarcinoma all exhibited high HER2 expression (stain, 3,3'-diaminobenzidine; magnification, x400). HER2, human epidermal growth factor receptor 2.

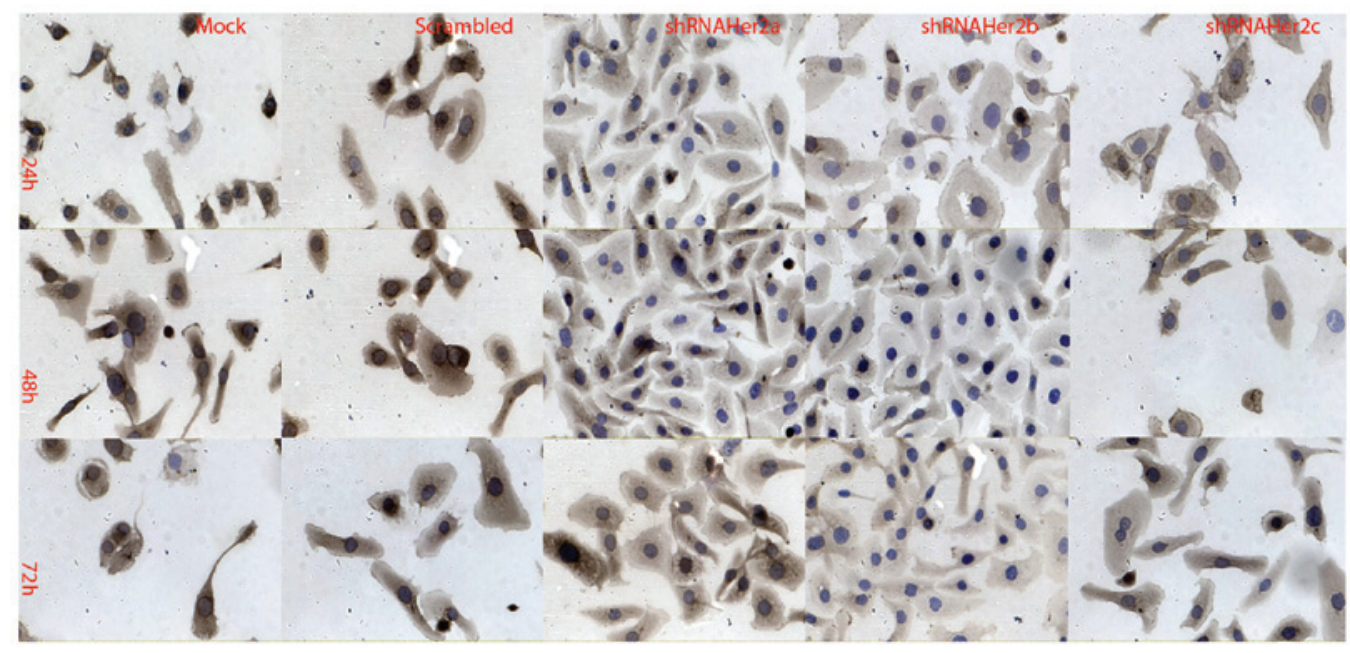

Figure 2. Growth inhibition ratio. The inhibition of HER2 expression exhibited by the shRNAb group was significantly higher than that of the other groups. (stain, 3,3'-diaminobenzidine; magnification, x400). shRNA, small hairpin RNA.

Plasmid construction. A total of three plasmids containing different shRNAs against various sections of the HER2 gene were designed by Vector NTI Advance 11.0 software (InforMax Inc., Bethesda, MD, USA) according to the human HER2 gene sequence (Genbank no. NM_001182801.1). shRNA fragments were synthesized using the T7 RNA polymerase promoter (Message Muter ${ }^{\mathrm{TM}}$ shRNA Production Kit; Epicentre, Madison, WI, USA) and cloned into pSliencer T7 vectors at the HindIII and BamHI restriction enzyme sites. The oligonucleotides contain a sense strand with 21 nucleotides followed by a short hairpin sequence (GAACGAAG). The reverse complement of the sense strand contains five thymines, which functions as a stop signal for RNA polymerase III transcription. The oligonucleotides were annealed under the following conditions: incubation at $90^{\circ} \mathrm{C}$ for $3 \mathrm{~min}$, followed by $37^{\circ} \mathrm{C}$ for $1 \mathrm{~h}$. Simultaneously, the pSilencer T7 vector, which is able to express shRNAs controlled by the T7 promoter, was digested using the HindIII and BamHI restriction enzymes. Subsequently, the fragments with a double-stranded structure were cloned into the pSilencer T7 vector via these two sites to form a recombinant plasmid with a T7 RNA polymerase promoter at the 5'-end. The plasmids were used as the negative control nonspecific shRNA. Finally, the following T7-shRNAs were obtained; Forward, 5'-GAT CCCCGAGATCACAGGTTACCTATTTCAAGAGAATAG GTAACCTGTGATCTCTTTTTTG-3' and reverse, 5'-GGG CTCTAGTGTCCAATGGATAAAGTTCTCTTATCCATT GGACACTAGAGAAAAATTCGA-3' for HER2-shRNAa; forward, 5'-GATCCCCAGAAATCTTAGACGAAGCAT TTCAAGAGAACGAAGCAGATTCTAAAGATTTTT 
Table I. HER2 expression levels (grey values) 24,48 and $72 \mathrm{~h}$ after transfection.

\begin{tabular}{|c|c|c|c|}
\hline \multirow[b]{2}{*}{ Group } & \multicolumn{3}{|c|}{ Time (h) } \\
\hline & 24 & 48 & 72 \\
\hline Mock & $1.935 \pm 0.042$ & $1.956 \pm 0.033$ & $2.054 \pm 0.045$ \\
\hline Scrambled & $2.002 \pm 0.098$ & $1.973 \pm 0.029$ & $2.039 \pm 0.032$ \\
\hline shRNAa & $1.638 \pm 0.045^{\mathrm{a}}$ & $1.864 \pm 0.021$ & $1.987 \pm 0.037$ \\
\hline shRNAb & $1.293 \pm 0.011^{\mathrm{a}}$ & $0.965 \pm 0.016^{\mathrm{b}}$ & $1.856 \pm 0.039$ \\
\hline shRNAc & $1.890 \pm 0.051$ & $1.993 \pm 0.042$ & $2.001 \pm 0.076$ \\
\hline
\end{tabular}

${ }^{a} \mathrm{P}<0.01$ and ${ }^{\mathrm{b}} \mathrm{P}<0.001$ vs. scrambled group. Data are presented as the mean \pm standard deviation. HER2, human epidermal growth factor receptor 2; shRNA, small hairpin RNA.

Table II. Reverse transcription-polymerase chain reaction results.

\begin{tabular}{lc}
\hline Group & $\begin{array}{c}\text { HER } 2 / \beta \text {-actin } \\
\text { (mean } \pm \text { standard deviation) }\end{array}$ \\
\hline shRNAa & $0.41 \pm 0.07^{\mathrm{a}}$ \\
shRNAb & $0.15 \pm 0.03^{\mathrm{b}}$ \\
shRNAc & $2.16 \pm 0.52$ \\
Scrambled & $1.92 \pm 0.45$ \\
Mock & $2.32 \pm 0.69$
\end{tabular}

${ }^{\mathrm{a}} \mathrm{P}<0.01$ and ${ }^{\mathrm{b}} \mathrm{P}<0.001$ vs. scrambled group. Data are presented as the mean \pm standard deviation. shRNA, small hairpin RNA.

Table III. Western blot analysis of HER2 protein levels.

\begin{tabular}{lc}
\hline Group & $\begin{array}{c}\text { HER2/marker } \\
\text { (mean } \pm \text { standard deviation) }\end{array}$ \\
\hline shRNAa & $1.32 \pm 0.08^{\mathrm{a}}$ \\
shRNAb & $0.09 \pm 0.02^{\mathrm{b}}$ \\
shRNAc & $1.66 \pm 0.25$ \\
Scrambled & $2.45 \pm 0.56$ \\
Mock & $2.42 \pm 0.39$
\end{tabular}

${ }^{\mathrm{a}} \mathrm{P}<0.01$ and ${ }^{\mathrm{b}} \mathrm{P}<0.001$ vs. scrambled control group. Data are presented as the mean \pm standard deviation. HER2, human epidermal growth factor receptor 2; shRNA, small hairpin RNA.

TG-3' and reverse, 5'-GGGTCTTTAGAATCTGCTTCG TAAGTTCTCTTGCTTCGTCTAAGATTTCTAAAAATT CGA-3' for HER2-shRNAb; forward, 5'-GATCCCCATGTT GGATGATTGACTCTTTCAAGAGATCTCAGTTAGTAG GTTGTATTTTTTG-3' and reverse, 5'-GGGTACAACCTA CTAACTGAGAAAGTTCTCTAGAGTCAATCATCCAAC ATAAAAATTCGA-3' HER2-shRNAc; forward, 5'-GAT CCCCGTCGTATACTGCCTCTATGTTCAAGAGAGTAT CTACGTCATATGCAGTTTTTTG-3' and reverse, 5'-GGG CTGCATATGACGTAGATACTTCAAGAGACATAGATG CAGTATACGTCTTTTTTG-3' for Scramble.

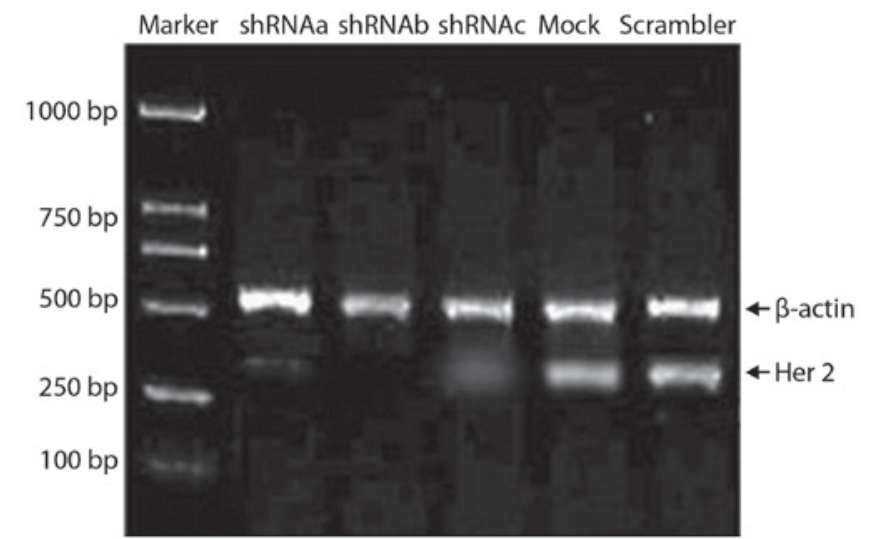

Figure 3. Semi-quantitative reverse transcription-polymerase chain reaction. shRNAa, b and c exhibited low HER 2 mRNA expression compared with that of the scrambled shRNA group. shRNA, short hairpin RNA.

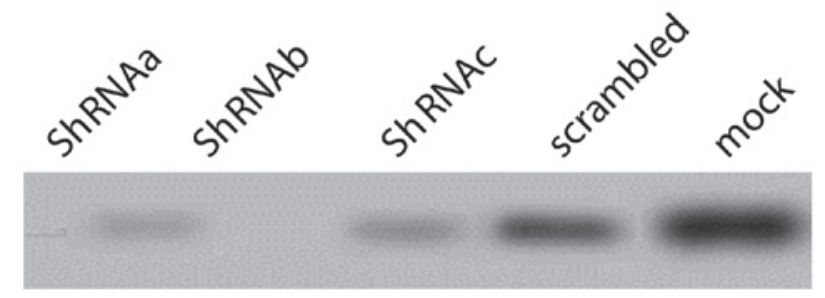

Figure 4. Western blot analysis of HER 2 expression in SKOV3 cells $24 \mathrm{~h}$ following transfection. HER2 protein levels were decreased in transfected shRNA cells compared with the scrambled shRNA group. shRNA, short hairpin RNA.

CCK-8 assay. CCK-8 was used to detect SKOV3 cell growth prior to and following treatment with HER 2 shRNA and CBP. The cells were seeded in a 96-well plate (BD Biosciences, Franklin Lakes, NJ, USA) and the cell line was digested using $0.25 \%$ Trypsin-EDTA BioReagent solution (Sigma-Aldrich, St. Louis, MO, USA) and counted. Next, the cells were inoculated into 96-well plates at 5x10,000, 2.5x10,000, 2x10,000, $1.5 \times 10,000,1 \times 10,000$ or $0.5 \times 10,000$ cells/well and grown in $200 \mu 1$ culture medium. Subsequently, $10 \mu$ CCK28 (1:10) was added into each well and the plates were incubated for $4 \mathrm{~h}$. The plates were treated with scramble control $(0.075 \mu \mathrm{g})$, shRNAa, -b, -c (0.075 $\mu \mathrm{g})$, CBP $(60 \mathrm{mg} / \mathrm{ml})$ or shRNAb 
Table IV. Optical density values of SKOV3 cells after transfection with shRNAs at various time points.

\begin{tabular}{|c|c|c|c|c|c|}
\hline \multirow[b]{2}{*}{ Group } & \multicolumn{5}{|c|}{ Time (days) } \\
\hline & 1 & 2 & 3 & 4 & 5 \\
\hline Control & 1.381 & 1.592 & 1.633 & 1.925 & 1.939 \\
\hline shRNAa & 1.154 & 1.093 & 1.211 & 1.643 & 1.623 \\
\hline shRNAb & 1.066 & 0.949 & 1.273 & 1.471 & 1.565 \\
\hline shRNAc & 1.262 & 1.173 & 1.708 & 2.025 & 1.874 \\
\hline Carboplatin & 0.863 & 1.037 & 0.784 & 0.412 & 0.235 \\
\hline
\end{tabular}

shRNA, small hairpin RNA.

Table V. Optical density values of SKOV3 cells after treatment with carboplatin, RNA interference or a combination at various time points.

\begin{tabular}{lccccr}
\hline & \multicolumn{5}{c}{ Time (days) } \\
\cline { 2 - 5 } Group & 1 & 2 & 3 & 4 & 5 \\
\hline Control & 1.381 & 1.592 & 1.633 & 1.925 & 1.939 \\
Carboplatin & 0.863 & 1.037 & 0.784 & 0.412 & 0.235 \\
shRNAb & 1.066 & 0.949 & 1.273 & 1.471 & 1.565 \\
shRNAb + carboplatin & 0.807 & 0.966 & 0.565 & 0.303 & 0.197 \\
\hline
\end{tabular}

shRNA, short hairpin RNA.

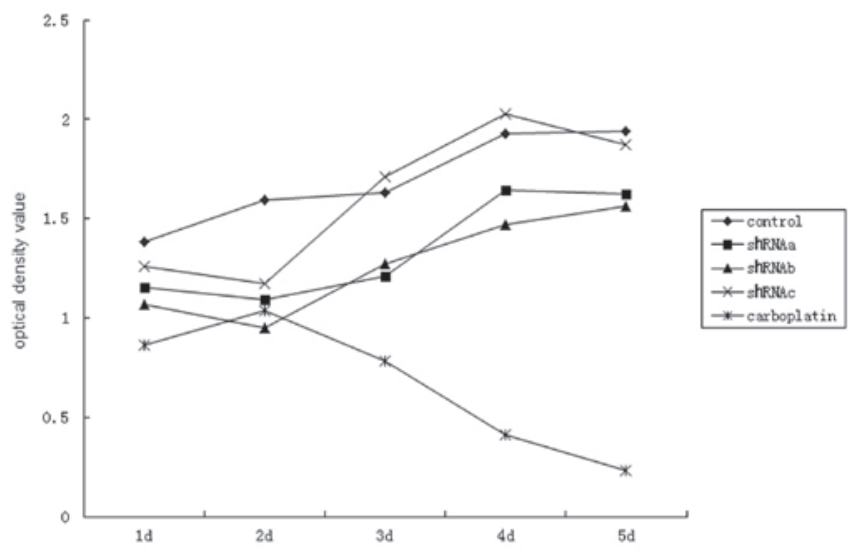

Figure 5. Growth inhibitory curve demonstrating the optical density values of SKOV3 cells following transfection with control, shRNAs and carboplatin at various time points. The growth of SKOV3 cells transfected with carboplatin was most significantly inhibited when compared with the control and shRNA groups. shRNA, small hairpin RNA.

$(0.075 \mu \mathrm{g})+\mathrm{CBP}(200 \mu \mathrm{l})(12 \mathrm{~h}$ after transfection $)$ and incubated for $4 \mathrm{~h}$. The optical densities were then analyzed using a spectrophotometer (SP-3000 Nano; Optima-Inc., Tokyo, Japan) at a wavelength of $450 \mathrm{~nm}$ and used to plot cell growth curves.

Statistical analysis. Data are presented as the mean \pm standard deviation. The two-sample Kolmogorov-Smirnov rank sum test and the Mann-Whitney U test were performed using

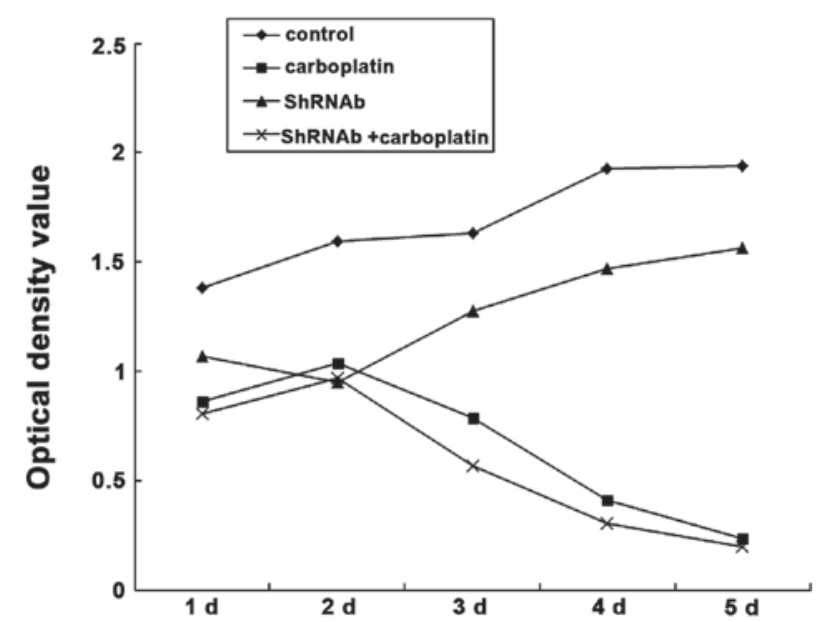

Figure 6. Growth curve demonstrating the effect of transfection with control, shRNAb and carboplatin + shRNAb on the chemosensitivity of SKOV3 cells at various time points. shRNAb treatment combined with carboplatin exhibited the highest inhibitory effect when compared with the other groups. shRNA, short hairpin RNA.

SPSS 20.0 software (IBM Corp., Armonk, NY, USA). P<0.05 was considered to indicate a statistically significant difference.

\section{Results}

HER2 overexpression in ovarian cancer tissues and SKOV3 cells. IHC analysis revealed that HER2 was overexpressed in 
ovarian cancer tissues and the SKOV3 ovarian cancer cell line, when compared with normal ovarian tissues. Normal ovarian cells exhibited a low to moderate HER2 expression of HER2, whereas primary ovarian cancer tissues and ovarian cancer cells exhibited moderate to high HER2 expression (Fig. 1). In addition, the IHC analysis revealed that the HER2 expression levels in ovarian cancer tissues (grey value, 1.9348 \pm 0.0183 ) were significantly higher compared with the normal ovarian tissues (grey value, 1.1085 $\pm 0.0116 ; \mathrm{P}<0.01$; Fig. 1).

Analysis of inhibition ratio. The inhibition of HER2 expression exhibited by the shRNAb group was significantly higher when compared with the shRNAa group $(\mathrm{P}<0.01)$; however, no inhibitory effect was observed in the shRNAc, mock or pSi-scrambled shRNA groups. After $24 \mathrm{~h}$, the inhibitory effect of shRNAa decreased and was not evident at $72 \mathrm{~h}$. The highest inhibition rate was observed in the shRNAb group, particularly $48 \mathrm{~h}$ after transfection, and the inhibitory effect remained evident $72 \mathrm{~h}$ after transfection (Fig. 2 and Table I).

Semi-quantitative RT-PCR. SKOV3 cells were transfected with shRNAs and observed after $24 \mathrm{~h}$. The results revealed that transfection with shRNAb significantly decreased the expression levels of HER2 mRNA (Fig. 3) and protein (Fig. 4), when compared with the scrambled-shRNA. In addition, shRNAa exhibited weak interference, while shRNAc exhibited no significant inhibitory effect on HER2 mRNA or protein expression (Fig. 3 and Table II).

Western blot analysis. SKOV3 cells were transfected with shRNAs and observed after $24 \mathrm{~h}$. The results revealed the presence of a major protein band of $60 \mathrm{kD}$ in the scrambled and mock groups; however, no significant difference was identified between the two groups. By contrast, the bands were less evident in the shRNAa and shRNAc groups, with no statistically significant difference between the two groups, and the shRNAb band was almost not visible. These results revealed that shRNAb efficiently inhibited HER2 expression (Fig. 4 and Table III).

Cell growth curve. The inhibitory effect of shRNAb and CBP on cell growth was found to be significant at day 1 after transfection, while shRNAa also exhibited an inhibitory effect. shRNAb was shown to exhibit the most significant effect at day 2 after transfection; however, the inhibition was gradually reduced. Therefore, sustained and effective inhibition of cell growth was observed following CBP treatment (Table IV and Fig. 5).

RNA interference and chemosensitivity. As shown in Figure 6, shRNA targeting the HER2 gene effectively inhibited HER2 expression in SKOV3 cells. The inhibitory effect of $\mathrm{CBP}+\mathrm{shRNAb}$ was the most significant, when compared with that of the other groups (Table V and Fig. 6). The results indicated that RNA interference may improve chemosensitivity to CBP chemotherapy.

\section{Discussion}

According to the GLOBOCAN 2012 of the World Health Organization, 239,000 cases of ovarian cancer were reported in females and 152,000 mortalities occurred worldwide in 2012 (26). Thus, ovarian cancer is the seventh most common type of cancer and the eighth most common cause of cancer-associated mortality in females. The average annual incidence rate of ovarian cancer is 6.3 per 100,000 individuals worldwide and 6.0 per 100,000 individuals in China $(27,28)$. Due to ineffective screening and the insidious progression of the disease, $\sim 75 \%$ of cases are diagnosed at a late stage, where cancer cells may have already spread throughout the abdominal cavity, leading to peritoneal carcinomatosis (29). Currently, the main treatment for ovarian cancer includes a combination of cytoreductive surgery and platinum-based chemotherapy (30). Initially, patients are highly responsive to chemotherapy and frequently exhibit a complete clinical response. However, the majority of these patients, particularly those at an advanced stage, relapse after an average period of 18 months and progressively develop drug resistance to a variety of chemotherapeutics $(29,30)$. As a result, the prognosis of patients at late stages of the disease is extremely poor. Clinical data has demonstrated that the five-year survival rate is $<25-35 \%$, which is mainly attributed to chemoresistance (29). Since cisplatin was approved for use in testicular and ovarian cancers by the U.S. Food and Drug Administration (FDA) in 1978, it has been used in the treatment of ovarian cancer. CBP has been found to have a comparable efficacy to cisplatin, and improved tolerance to the therapy and quality of life have been observed in chemotherapy patients treated with CBP (31). Thus, at present, $\mathrm{CBP} /$ paclitaxel combination is the standard chemotherapeutic treatment for ovarian cancer patients. However, the prognosis for patients with advanced ovarian cancer remains poor due to acquired chemoresistance.

Ovarian cancer has been previously reported to present as a heterogeneous group of tumors, rather than a single clinical entity. At the initial stages of the disease, the prognosis for ovarian cancer is associated with three main parameters, which include histological (32) and biological factors (hormone receptors, BRCA1/2, vascular endothelial growth factor, EGFR, HER2 and molecular signatures) (33). Although tumor biology at the molecular level appears to be particularly important in this type of cancer, prognostic and predictive biomarkers have not been applied in clinical practice (34). The HER2 gene is overexpressed in a number of malignant human cancer tissues and cancer cell lines, and has been associated with a reduced relapse time, chemoresistance and overall survival rate in patients with ovarian, breast or other types of cancer (35). The oncogene, HER2, belongs to the EGFR tyrosine kinase receptor family. Overexpression of HER2 stimulates several intracellular signaling pathways, which are involved in cell proliferation and migration, while positive HER2 status has been found to correlate with a poor prognosis in breast cancer (36). Thus, HER2 is currently recognized as an important therapeutic target. Trastuzumab is a monoclonal antibody that was approved by the U.S. FDA in 1998 for the treatment of HER2-overexpressing breast cancer and is able to specifically interact with the extracellular domain of HER2 (16). However, trastuzumab has been found to result in side-effects, including cardiomyopathy and hypersensitivity; thus, alternative therapies are required for the treatment of this disease (37). Notably, the antibody drug conjugate, trastuzumab emtansine, has been found to significantly prolong progression-free and overall survival in HER2-positive and advanced breast cancer patients (16). According to these results, the downregulation of HER2, in combination with other 
therapeutic strategies, may exert a synergetic effect. RNAi is a technology that may be used to knockdown the expression of a target gene with high specificity and selectivity. It may be continuously synthesized by the host cell and is transcribed by RNA polymerase II or III on the expression cassette, which is more efficient and durable (38).

In the present study, the expression level of HER2 was found to be significantly increased in human ovarian cancer tissues when compared with that in normal ovarian tissues. Furthermore, among the three pairs of shRNA oligonucleotides against HER2, only shRNAb significantly inhibited HER2 expression in SKOV3 cells, as demonstrated by IHC analysis and semi-quantitative RT-PCR. Subsequently, shRNAb was used to transfect SKOV3 cells to determine the effect on chemosensitivity to $\mathrm{CBP}$. The results revealed that transfection with shRNAb, in combination with CBP, significantly decreased the expression level of HER2 and increased chemosensitivity of SKOV3 cells to CBP.

The results of the current study were similar to those of Faltus et al (39), in which the authors reported the antitumor effects of HER2 shRNA in vitro. In addition, in the present study, HER2 shRNA transfection and CBP treatment were combined, which revealed that HER2 downregulation facilitated CBP sensitivity in ovarian SKOV3 cancer cells.

In conclusion, the results of the current study indicated that HER2 expression downregulation significantly inhibited ovarian cancer cell growth and promoted chemosensitivity. Thus, HER2 may a potential therapeutic target for the treatment of ovarian cancer. Furthermore, combined treatment with HER2 shRNA and chemotherapy may present an effective strategy for ovarian cancer treatment.

\section{References}

1. Gentry-Maharaj A and Menon U: Screening for ovarian cancer in the general population. Best Pract Res Clin Obstet Gynaecol 26: 243-256, 2012.

2. Klint A, Tryggvadóttir L, Bray F, et al: Trends in the survival of patients diagnosed with cancer in female genital organs in the Nordic countries 1964-2003 followed up to the end of 2006. Acta Oncol 49: 632-643, 2010.

3. Permuth-Wey J and Sellers TA: Epidemiology of ovarian cancer. Methods Mol Biol 472: 413-437, 2009.

4. Zahedi P, Yoganathan R, Piquette-Miller M and Allen C: Recent advances in drug delivery strategies for treatment of ovarian cancer. Expert Opin Drug Deliv 9: 567-583, 2012.

5. Shih IeM and Davidson B: Pathogenesis of ovarian cancer: clues from selected overexpressed genes. Future Oncol 5: 1641-1657, 2009.

6. Bulun SE: Uterine fibroids. N Engl J Med 369: 1344-1355, 2013.

7. Groenen LC, Nice EC and Burgess AW: Structure-function relationships for the EGF/TGF-alpha family of mitogens. Growth Factors 11: 235-257, 1994.

8. Lemke G: Neuregulins in development. Mol Cell Neurosci 7: 247-262, 1996.

9. Berchuck A, Kamel A, Whitaker R, et al: Overexpression of HER-2/neu is associated with poor survival in advanced epithelial ovarian cancer. Cancer Res 50: 4087-4091, 1990.

10. Berchuck A, Rodriguez G, Kinney RB, et al: Overexpression of HER-2/neu in endometrial cancer is associated with advanced stage disease. Am J Obstet Gynecol 164: 15-21, 1991.

11. Tandon AK, Clark GM, Chamness GC, et al: HER-2/neu oncogene protein and prognosis in breast cancer. J Clin Oncol 7: 1120-1128, 1989

12. Meden $\mathrm{H}$ and Kuhn W: Overexpression of the oncogene c-erbB-2 (HER2/neu) in ovarian cancer: a new prognostic factor. Eur J Obstet Gynecol Reprod Biol 71: 173-179, 1997.

13. Slamon DJ, Clark GM, Wong SG, et al: Human breast cancer: correlation of relapse and survival with amplification of the HER-2/neu oncogene. Science 235: 177-182, 1987.
14. Slamon DJ, Godolphin W, Jones LA, et al: Studies of the HER-2/neu proto-oncogene in human breast and ovarian cancer. Science 244: 707-712, 1989.

15. Carter P, Presta L, Gorman CM, et al: Humanization of an anti-p185HER2 antibody for human cancer therapy. Proc Natl Acad Sci USA 89: 4285-4289, 1992.

16. Verma S, Miles D, Gianni L, et al; EMILIA Study Group: Trastuzumab emtansine for HER2-positive advanced breast cancer. N Engl J Med 367: 1783-1791, 2012.

17. Wu Y, Zhang Y, Wang M, et al: Downregulation of HER3 by a novel antisense oligonucleotide, EZN-3920, improves the antitumor activity of EGFR and HER 2 tyrosine kinase inhibitors in animal models. Mol Cancer Ther 12: 427-437, 2013.

18. Tai W, Mahato R and Cheng K: The role of HER2 in cancer therapy and targeted drug delivery. J Control Release 146: 264-275, 2010.

19. Ferracin M, Bassi C, Pedriali M, et al: miR-125b targets erythropoietin and its receptor and their expression correlates with metastatic potential and ERBB2/HER2 expression. Mol Cancer 12: 130, 2013.

20. Corsi F, Fiandra L, De Palma C, et al: HER2 expression in breast cancer cells is downregulated upon active targeting by antibody-engineered multifunctional nanoparticles in mice. ACS Nano 5: 6383-6393, 2011

21. Rho O, Kim DJ, Kiguchi K and Digiovanni J: Growth factor signaling pathways as targets for prevention of epithelial carcinogenesis. Mol Carcinog 50: 264-279, 2011.

22. Campone M,Noël B, Couriaud C, et al: c-Myc dependent expression of pro-apoptotic Bim renders HER2-overexpressing breast cancer cells dependent on anti-apoptotic Mcl-1. Mol Cancer 10: 110, 2011.

23. Maillard PV, Ciaudo C, Marchais A, et al: Antiviral RNA interference in mammalian cells. Science 342: 235-238, 2013.

24. Mutch DG and Prat J: 2014 FIGO staging for ovarian, fallopian tube and peritoneal cancer. Gynecol Oncol 133: 401-404, 2014.

25. Livak KJ and Schmittgen TD: Analysis of relative gene expression data using real-time quantitative PCR and the 2(-Delta Delta C(T)) Method. Methods 25: 402-408, 2001.

26. World Health Organization: GLOBOCAN 2012: Estimated Cancer Incidence and Mortality Worldwide in 2012. http:// globocan.iarc.fr. Accessed December 12, 2013.

27. Jemal A, Tiwari RC, Murray T, et al; American Cancer Society: Cancer statistics, 2004. CA Cancer J Clin 54: 8-29, 2004.

28. Buys SS, Partridge E, Black A, et al; PLCO Project Team: Effect of screening on ovarian cancer mortality: the Prostate, Lung, Colorectal and Ovarian (PLCO) Cancer Screening Randomized Controlled Trial. JAMA 305: 2295-2303, 2011.

29. Cannistra SA: Cancer of the ovary. N Engl J Med 351: 2519-2529, 2004.

30. Colombo N, Peiretti M, Parma G, et al; ESMO Guidelines Working Group: Newly diagnosed and relapsed epithelial ovarian carcinoma: ESMO Clinical Practice Guidelines for diagnosis, treatment and follow-up. Ann Oncol 21 (Suppl 5): S23-S30, 2010

31. du Bois A, Lück HJ, Meier W, et al; Arbeitsgemeinschaft Gynäkologische Onkologie Ovarian Cancer Study Group: A randomized clinical trial of cisplatin/paclitaxel versus carboplatin/paclitaxel as first-line treatment of ovarian cancer. J Natl Cancer Inst 95: 1320-1329, 2003.

32. Levanon K, Crum C and Drapkin R: New insights into the pathogenesis of serous ovarian cancer and its clinical impact. J Clin Oncol 26: 5284-5293, 2008.

33. Steffensen KD, Waldstrøm M, Jeppesen U, et al: The prognostic importance of cyclooxygenase 2 and HER2 expression in epithelial ovarian cancer. Int J Gynecol Cancer 17: 798-807, 2007.

34. Colombo PE, Fabbro M, Theillet C, et al: Sensitivity and resistance to treatment in the primary management of epithelial ovarian cancer. Crit Rev Oncol Hematol 89: 207-216, 2014.

35. Berchuck A, Kamel A, Whitaker R, et al: Overexpression of HER-2/neu is associated with poor survival in advanced epithelial ovarian cancer. Cancer Res 50: 4087-4091, 1990.

36. Chao WR, Lee MY, Lin WL, et al: HER2 amplification and overexpression are significantly correlated in mucinous epithelial ovarian cancer. Hum Pathol 45: 810-816, 2014.

37. Shawver LK, Slamon D and Ullrich A: Smart drugs: tyrosine kinase inhibitors in cancer therapy. Cancer Cell 1: 117-123, 2002.

38. Rao DD, Vorhies JS, Senzer N and Nemunaitis J: siRNA vs. shRNA: similarities and differences. Adv Drug Deliv Rev 61: 746-759, 2009

39. Faltus T, Yuan J, Zimmer B, et al: Silencing of the HER2/neu gene by siRNA inhibits proliferation and induces apoptosis in HER2/ neu-overexpressing breast cancer cells. Neoplasia 6: 786-795, 2004. 